\title{
A Survey Study of English Speaking Strategies Use: Evidence from Chinese High School Students of International Department
}

\author{
Hong Zhou ${ }^{1} \&$ Yufang Feng ${ }^{2}$ \\ ${ }^{1}$ Guangling College of Yangzhou University, Yangzhou, Jiangsu, China \\ ${ }^{2}$ School of International Studies, Yangzhou University, Yangzhou, Jiangsu, China \\ Correspondence: Yufang Feng, School of International Studies, Yangzhou University, Yangzhou, Jiangsu, \\ China.
}

Received: August 26, 2021

Accepted: September 30, 2021

Online Published: October 22, 2021

doi:10.5539/jel.v10n6p54

URL: https://doi.org/10.5539/jel.v10n6p54

\begin{abstract}
This study explores the status quo of speaking strategies used by Chinese High School Students of International Department by using both questionnaire and interview. The participants were 90 second-year Chinese High School Students of International Department, and then the data were analyzed by SPSS 18.0. The study yields certain results. First, Chinese High School Students of International Department employ English speaking strategies at a medium level in general. Second, there are differences between higher achievers and lower achievers in the use of speaking strategies. Third, students' use of speaking strategies is significantly correlated with students' English proficiency. Pedagogical implications for teachers and students are discussed in the end.
\end{abstract}

Keywords: language learning strategies, English speaking strategies, Chinese high school students of international department, survey study

\section{Introduction}

Speaking strategies, as one of the most dynamic factors affecting learner's ability, have significant influence on students' speaking ability. Learn to use speaking strategies can be beneficial for language learners to carry out active conversations. However, due to the influence of traditional teaching methodology, most Chinese students have low proficiency in oral English. Many Chinese learners cannot speak English fluently even though they have been studying English for many years, which is known as the unsatisfactory phenomenon of "dumb English". Besides, although there are many studies on learning strategies both at home and abroad, few studies have investigated the general pattern of speaking learning strategies, especially when the subjects are Chinese High School Students of International Department. Therefore, it is crucial to investigate how learners use speaking learning strategies, which is beneficial to learner's communicative ability.

Consequently, this study aims at investigating the overall tendency of English speaking strategy used by Chinese High School Students of International Department, the differences between high-achievers and low-achievers in terms of speaking strategy use as well as the relationship between speaking strategy use and oral English achievements. The study takes a mixed approach, using both questionnaire and interview to survey the following three questions: (1) What are the overall tendencies of the English speaking strategy employed by Chinese High School Students of International Department? (2) What are the differences in terms of speaking strategy use between higher achievers and lower achievers? (3) Is there any correlation between speaking strategy use and oral English proficiency? If yes, what is the relationship? Quantitative research is conducted to describe and test relationships while qualitative research is used to explore the depth and complexity inherent of English speaking strategies.

\section{Literature Review}

\subsection{Definition of Speaking Strategy}

Just as Rod Ellis says, “The concepts of 'strategy' is a fuzzy one” (1994, p. 529), it is not easy to tie down the definition of learning strategies. In fact, "different researchers used different terms and different concepts" (Oxford \& Crocall, 1989, p. 414), and "there had been no consensus on the definition and classification of strategies" (O’Malley \& Chamot, 1990, p. 114). Chamot (1987) states, "learning strategies are techniques, approaches or deliberate actions that students take in order to facilitate the learning, recall of both linguistic and 
content area information." Rubin (1987) insists that learning strategies are strategies which contribute to the development of the language system which the learner constructs and affects learning directly. Oxford (1989) believes that language learning strategies are behaviors or actions which learners use to make language learning more successful, self-directed and enjoyable.

Although there is not a consensus about the definition of learning strategies, most of them emphasize that the purpose of using strategy is to prompt the learning efficiency, and the essence of strategy is the learners' action which can be outer or inner. In light of the previous definitions, this paper views language learning strategies as mental and behavioral approaches taken by learners consciously or unconsciously to facilitate learning directly or indirectly. Considered as a part of learning strategies, speaking strategies are closely related to learning strategies. Similarly, speaking strategies are strategies that language learners utilize in their speech to help realize their speech acts in a foreign language.

\subsection{Classification of Speaking Strategy}

Just as the definition of language learning strategies is hard to tie down and vary a lot, so is the classification of language learning strategies accordingly. Among those classifications of learning strategies, O'Malley and Chamot's trichotomy (1990) and Oxford's dichotomy (1990), gain the widest popularity.

O'Malley and Chamot (1990) divides language learning strategy into three categories: metacognitive strategies, cognitive strategies and social/affective strategies. Oxford (1990) divides the learning strategy into direct or indirect category according to whether the strategy has a direct effect on the learning process. Direct strategies consist of "strategies that directly involve the target language" and they "require mental processing of the language" (Oxford, 1990, p. 37). "Indirect strategies provide indirect support for language learning through focusing, planning, evaluating, seeking opportunities, controlling anxiety, increasing cooperation and empathy and other means" (Oxford, 1990, p. 151). Direct strategies include cognitive strategy, memory strategy and compensation strategy. In contrast, indirect strategies include metacognitive strategy, affective strategy and social strategy.

Similarly, based on Oxford's (1990) classification, this paper classifies speaking strategies into six categories: Cognitive speaking strategies, Memory speaking strategies, Compensation speaking strategies, Metacognitive speaking strategies, Affective speaking strategies and Social speaking strategies.

\subsection{Study at Home and Abroad}

To date, many researchers focus on language learning strategies in the aspect of listening (Arnold, 2000; Jane, 2004), reading (Peter, Pearson, \& Scott, 2008; Jessie, 2016), and writing (A Suresh Canagarajah, 2011; Rui, Guangwei, \& Peter, 2014). However, little research has been undertaken on how language learners deploy or develop speaking strategies (Yunnus \& Singh, 2014). Research shows that effective use of speaking strategies can improve oral proficiency. McDonough (1995) reviewed strategies for speaking in his book, and cited one study conducted by O'Malley and Chamot (1990) as empirical evidence, in which the group given explicit training in metacognitive, cognitive, and social/affective strategies improved significantly more than the control group. Bruen (2002) found that orally more proficient students employ more strategies than less proficient ones by carrying out the study on the foreign LLS of successful learners involving 100 students of German in a university in Ireland. Ghaleb Rabab'ah (2016) examines the effect of communication strategy instruction on EFL students' oral communicative ability and their strategic competence. The findings revealed that participants in the strategy training group significantly outperformed the control group in their IELTS speaking test scores, and the participants in the strategy training group used more CSs, which could be attributed to the CS training program. Norimah Mohamad Yunus, Kuldip Kaur a/p Maktiar Singh (2014) investigates 80 MDAB (Mengubah Destini Anak Bangsa': a program for poor Bumiputra students to gain entrance into pre-diploma courses at UiTM branch campuses) students' use of indirect strategies in speaking, and find that the use of the social strategies is higher and more significant compared to the metacognitive and affective strategies.

However, the studies of speaking learning strategies in China began much later than other countries. Learners at different proficiency levels favour different speaking strategies. Huang (1984) investigated the learning strategies in oral communication used by Chinese students of English as a second language in China consisted of identification of the general strategies and specific techniques for improving oral proficiency, and assessment of the effects of some of them on achievement, which was the first study on speaking strategies in China. In 1990, Chen Si-Qing published "A study of communication strategies in interlanguage production by Chinese EFL learners," which indicated that the frequency, type, and effectiveness of strategies employed by learners varied according to their proficiency level and the language distance between the learners' native and second languages (Chen, 1990). Shen (2009) investigated the adults' speaking learning strategy use in Shanghai, which showed 
that the use of speaking learning strategies of Shanghai area was not so optimistic. The most frequently used strategies are cognitive and memory strategies, while the least used strategies are affective strategies. Among those researches on speaking learning strategies, most target college students and ordinary high school students, while few focus on High School Students of International Department. To fill this gap, this paper set out to explore the status quo of speaking strategies used by Chinese High School Students of International Department by surveying the general pattern of students' English speaking strategies, to compare the differences between high achievers and low achievers of oral English strategy use, and to examine the correlation between speaking strategy use and students' oral English proficiency.

\section{Method}

This section explains participants, data collection and data analysis.

\subsection{Participants}

This study involves 90 second-year Chinese High School Students of International Department from Yangzhou High School, Yangzhou New Oriental Foreign Language School and Liyang High School in Jiangsu Province, China. High School Students of International Department are Chinese students who have international classes and aim at attending universities abroad after graduation. Ultimately, 80 questionnaires are found valid and 10 invalid questionnaires are eliminated.

Compared with common high school students, Chinese High School Students of International Department have additional oral courses and put more emphasis on spoken English as most of them have a strong motivation of going abroad. Thus, they employ English speaking strategies more often, which is beneficial to conduct this research. In addition, the TOEFL oral scores are used to divide higher achievers and lower achievers. The division of the higher group and the lower group is determined by their ranking of oral scores. The top $25 \%$ of the subjects are defined as higher achievers while the bottom $25 \%$ of the subjects constitute the lower achievers.

\subsection{Instrument}

The survey tools include a questionnaire and an interview to collect information about the English speaking strategy use of Chinese High School Students of International Department. Based on Oxford's (1990) Strategies Inventory for Language Learning (SILL), the researcher designs the questionnaire and makes proper adaptations to make it more suitable for the actual situation of Chinese High School Students of International Department. The questionnaire includes two parts, background information and questions. The former provides personal background information, including name, gender, the grade of TOEFL oral test, etc. The latter describes the students' strategy use involved in spoken English learning activities, which contains 45 items of six categories. That is, 1) Memory speaking strategies, four items; 2) Cognitive speaking strategies, eight items; 3) Compensation speaking strategies, eight items; 4) Meta-cognitive speaking strategies, ten items; 5) Affective speaking strategies, ten items; 6) Social speaking strategies, five items. Besides, the questionnaire also uses a five-point Likert scale ranging from one to five to measure each item of the English speaking strategies.

"Qualitative data analysis adds richness and detail which can help answer nagging questions of 'why' and 'how' that may remain unaddressed by purely statistical results" (Ehrman \& Oxford, 1991, p. 324). One questionnaire is not adequate to know the detailed information of Chinese High School Students of International Department. Then the qualitative research-interview, is added to collect more specific data so as to provide supplementary explanations for the result of the questionnaire. The interview chooses ten students to collect specific strategies used in oral English. All the interviews are tape-recorded and transcribed afterwards, eliminating irrelevant information about English speaking strategies. Then the data collected from the interview is used to provide supplementary explanations for the result of the questionnaire.

\subsection{Data Analysis}

According to the arrangement, the subjects were given 15 minutes to finish the questionnaire, and then an interview was conducted. In terms of the overall tendencies of English speaking strategy employed by Chinese High School Students of International Department, the analysis of these statistics is based on the scale described by Oxford (1990): low, medium and high (see Table 1). 
Table 1. Descriptive statistics

\begin{tabular}{lll}
\hline Mean score & Frequency & Evaluation \\
\hline $1.0-1.4$ & Low & Never \\
$1.5-2.4$ & & Usually not \\
$2.5-3.4$ & Medium & Sometimes \\
$3.5-4.4$ & High & Usually \\
$4.5-5.0$ & & Always \\
\hline
\end{tabular}

Data collected were analyzed by SPSS 18.0, which includes three steps: (1) the researchers first calculated and analysed the mean score and standard deviation of the use of English speaking strategies (see Table 2). (2) The subjects' oral scores of TOEFL in the top $1 / 4$ ( 20 people) and the bottom 1/4 (20 people) were divided into high achievers and low achievers respectively. The independent samples t-test (see Table 3) was used to analyse the differences between higher achievers and lower achievers. (3) The relationship between speaking strategy use and oral English proficiency was calculated by Pearson correlation (see Table 4).

\section{Results and Discussions}

\subsection{Overall Tendency of English Speaking Strategy Used by Chinese High School Students of International Department}

Table 2 shows the descriptive statistical results of the speaking strategies employed by Chinese High School Students of International Department. The results reveal that Chinese High School Students of International Department use speaking strategies at a medium level, for the mean score of the five categories fall between 2.5 and 3.4, except for the Memory speaking strategies. Of the six speaking strategies categories, the most commonly used speaking learning strategies are Memory speaking strategies (Mean=3.58, $\mathrm{SD}=.77$ ), followed by Compensation speaking strategies (Mean=3.41, $\mathrm{SD}=.58$ ), Meta-cognitive speaking strategies (Mean=3.39, $\mathrm{SD}=.81$ ), Cognitive speaking strategies (Mean=3.36, $\mathrm{SD}=.67$ ), Affective speaking strategies (Mean=3.08, $\mathrm{SD}=.63$ ), and Social speaking strategies come the last (Mean=3.05, $\mathrm{SD}=.56$ ). In other words, direct strategies are more frequently used than indirect strategies. Memory speaking strategies rank first among the six broad categories, with an average mean of 3.58. Fluent oral English requires a large amount of vocabulary and abundant knowledge preparation, thus it is not strange that students use Memory speaking strategies at the highest frequency. Oxford believes that memory strategies can be powerful contributors to language learning (Oxford, 1990, p. 40). What worth mentioning is that Chinese High School Students of International Department use Affective speaking strategies and Social speaking strategies less frequently, and Social speaking strategies turn out to be the least used strategies. This research findings concur with Chu (2008) that social strategies were the least used strategy type by college students. According to the interview, students mention that they are afraid of making mistakes and even feel anxious when speaking. As a result, many potentially excellent language learners are naturally inhibited. Besides, most students lack cooperative consciousness, so they are less likely to cooperate with classmates to improve oral English.

Table 2. Descriptive statistics of the use of English speaking strategies

\begin{tabular}{llll}
\hline Category & & Mean & Standard Deviation \\
\hline Direct & Memory speaking strategies & 3.58 & .77 \\
Strategies & Cognitive speaking strategies & 3.36 & .67 \\
& Compensation speaking strategies & 3.41 & .58 \\
Indirect & Meta-cognitive speaking strategies & 3.39 & .81 \\
Strategies & Affective speaking strategies & 3.08 & .63 \\
& Social speaking strategies & 3.05 & .56 \\
\hline
\end{tabular}

\subsection{Differences Between Higher Achievers and Lower Achievers in Speaking Strategies}

As shown in Table 3, among the six broad categories of speaking strategies, the mean score of higher achievers is higher than the lower achievers, which means that the higher group uses strategies more frequently than the lower group. However, the p-value of Memory speaking strategies and Compensation speaking strategies (.527 and .488) is higher than .05 , which manifests that the variation between the two groups is not significant. On the other hand, we can see that the $\mathrm{p}$ values in the Cognitive speaking strategies $(\mathrm{p}=.000)$, Metacognitive speaking strategies $(\mathrm{p}=.000)$, Affective speaking strategies $(\mathrm{p}=.023)$ and Social speaking strategies $(\mathrm{p}=.013)$ are less than 0.05 , which means that the variations are at the significant levels. The most significant difference happens to 
Cognitive speaking strategies and Metacognitive speaking strategies, followed by Social speaking strategies and Affective speaking strategies. This suggests that these four strategies are employed by the higher group more frequently than the lower group.

Although Memory speaking strategies are the most frequently used strategies, the p-value is .527, which means no significant differences are found between the two groups. From the interview, we found that both higher achievers and lower achievers spend lots of time remembering new words, dialogues and sentence patterns. Therefore, both groups tend to use this strategy quite often to enhance their oral language learning.

As to Compensation speaking strategies, some points are worth noticing. Higher achievers are less likely to use Chinese or avoid difficult topics deliberately. Instead, they are more likely to use synonyms and make some predictions according to some clues, for the means of Q14 ("I use Chinese directly when I have unfamiliar words or sentences."), Q16 ("I avoid difficult expressions or topics when I speak English.") and Q17 ("I select the interesting or easy topics to interact with others when I speak English") of the higher achievers are 2.54, 3.27, 3.72 and of the lower achievers are 2.80, 3.38, 3.76.

Concerning Cognitive speaking strategies, there are significant differences between the two groups $(\mathrm{P}=.000)$. Although the differences of some specific strategies are not so noticeable, such as Q5 ("I repeat the sentences I heard to imitate its pronunciation and intonation.") (higher achievers, Mean=2.95; lower achievers, Mean=2.61; $\mathrm{p}=.305>.05$ ), Q8 ("I organize learner language segments and use them in oral English.") (higher achievers, Mean=3.63; lower achievers, Mean=3.14; $\mathrm{p}=.090>.05$ ) and Q11 ("I turn to translation when speaking English.") (higher achievers, Mean=3.40; lower achievers, Mean=3.33; $p=.792>.05$ ), higher achievers report adopting these strategies more often. In addition, higher achievers show much preference in the speaking strategies of $Q 6$ ("I improve intonation and pronunciation through various means.") (Mean=2.95, $\mathrm{SD}=.95$ ), Q10 ("I make full use of language material to increase language input.") (Mean=3.90, $\mathrm{SD}=1.01)$, and the differences are so significant that the p-value of these strategies even reaches .000.

In terms of Metacognitive speaking strategies, the two groups differ significantly $(\mathrm{p}=.0000)$. To some extent, students in the lower group cannot arrange and plan their English learning very well. Besides, they have problems monitoring and evaluating their learning process, and making timely adjustment. Such a result also conforms to the interview. Students in the lower group complain that they do not know how to use strategies effectively and they are always at a loss about how to manage their study.

Although Social speaking strategies are the least used category, the statistical result shows significant differences between higher achievers (Mean=3.36) and lower achievers (Mean= 2.63), with the p-value being .013. One point worth noticing is students' attitude to group work, such as Q43 ("I cooperate with classmates to improve my students."), Q44 ("I cooperate with high achievers to practice oral English."), higher achievers (Q43, Mean=3.31; Q44, Mean=3.32) favor group work much more than lower achievers (Q43, $\mathrm{Mean}=2.57$; $\mathrm{Q} 44$, Mean=2.66). Moreover, the differences are significant ( $\mathrm{Q} 43, \mathrm{P}=.012 ; \mathrm{Q} 44 \mathrm{P}=.010)$. This phenomenon may be attributed to the following reasons. This is partly due to the teacher's partial treatment, higher achievers are favored and given more opportunities to talk in class. Besides, higher achievers have more opportunities to express themselves in group work, for they are better at speaking English. It could be proved from the interview of the lower achievers:

In the oral English class, we have a lot of pair work and group work. As I am weak in oral English, I feel too nervous and shy to speak English. As a result, it is often the case that group members with better English proficiency talk a lot and I, for most of the time, only listen to them. (translation)

Table 3. Independent-samples T-test of speaking strategies between lower achievers and higher achievers

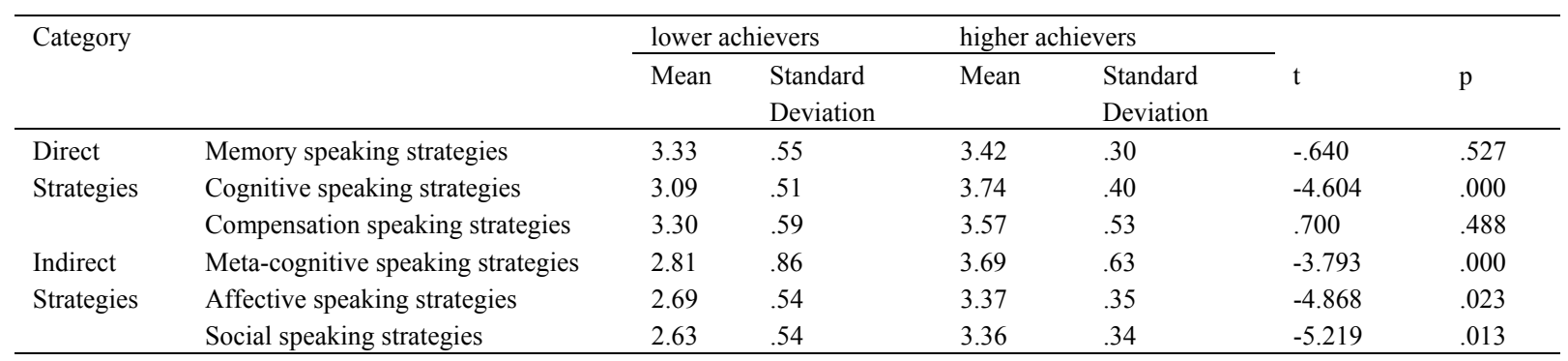




\subsection{Correlation Between the Speaking Strategies' Use of Chinese High School Students of International Department and Their oral English Proficiency}

As shown in Table 4, Cognitive speaking strategies $(\mathrm{r}=.304 * *)$, Compensation speaking strategies $\left(\mathrm{r}=.291^{* *}\right)$, Metacognitive speaking strategies $\left(\mathrm{r}=.342^{* *}\right)$, Affective speaking strategies $\left(\mathrm{r}=.374^{* *}\right)$ and Social speaking strategies $\left(\mathrm{r}=.560^{* *}\right)$ are positively correlated with students' English proficiency at the .01 level. And Social speaking strategies, Affective speaking strategies and Metacognitive speaking strategies are much more correlated with oral proficiency than Cognitive speaking strategies and Compensation speaking strategies. In contrast, there is no significant correlation between Memory speaking strategies $(\mathrm{r}=.077)$ and English proficiency. Memory speaking strategies appear to have some weak yet positive effects on vocal performance, but they are not statistically significant $(\mathrm{r}=.077)$.

Cognitive speaking strategies have a strong relationship with oral proficiency as the correlation coefficient is up to .304 at the .01 level. Cognitive speaking strategies are beneficial to language learning using reasoning, analyzing, summarizing and practicing, etc. Within the category, Q6 ("I improve intonation and pronunciation through various means.") and Q10 ("I make full use of language material to increase language input.") are positively related to oral proficiency. In contrast, Q12 ("I use rules of Chinese into oral English directly.") has a negative correlation with oral level, which means that the more one employs this strategy, the worse their achievements, and vice versa.

Metacognitive speaking strategies are positively and highly related to students' English proficiency $(\mathrm{r}=.342 * *)$, indicating that Metacognitive speaking strategies are conducive to improving the general level of oral proficiency. Research findings of many previous studies also show that there is a close relationship between Metacognitive speaking strategies and oral proficiency. Just as O'Malley and Chamot's research result shows, "students without metacognitive approaches are essentially learners without direction or opportunity to plan their learning, monitor their progress, or review their accomplishments and future learning directions" (O'Malley \& Chamot, 1990, p. 8). It also echoes with the research conducted by Tan and Tan (2010), who examined a metacognitive approach to the learning of Chinese language speaking, and the results demonstrate that good students devote greater attention to monitoring strategy. Besides, "teaching students metacognitive strategies is a valuable skill that helps students become more self-directed learners" (Shannon, 2008).

Within the affective category, Q32 ("I tell myself not to be nervous when I talk to others."), Q34 ("I encourage myself to speak English, although I am scared to."), Q35 ("I encourage myself to speak English, although sometimes I make mistakes or being laughing at."), Q36 ("I reward myself if I do well in oral English."), Q39 ("I write oral English learning diaries.") are all significantly related to oral proficiency. Oxford (1990, p. 140) figures that the learner's affective strategy is probably one of the biggest influences on language learning success or failure. Many studies on students' attitudes, anxieties or motivations have proved this idea: negative feelings have negative influences on learning English, such as disturbing expressions, even though the learner is proficient in the language he is learning; on the other hand, positive emotions and attitudes can make language learning more effective and enjoyable (Arnold, 2000; Carson \& Longhini, 2002). Therefore, it is necessary to monitor the affective factors in students' oral English learning. This is also supported by the descriptions of the interviewer:

I would feel a little nervous when I was speaking English, because of word obstacles and pronouncing problems. Still, I would encourage myself to speak English, for I know the more I talk English, the better my oral English would be. For example, I would say something positive to myself, such as "I can do it." and so on. (translation)

As for the social category, its correlation is the strongest $\left(\mathrm{r}=.560^{* *}\right)$ among the six broad categories, which indicates that Social speaking strategies contribute a lot to students' oral English proficiency. Explicitly speaking, Q41 ("I ask others to correct my mistakes when I communicate with others.") and Q42 ("I ask others to slow down or repeat what they said if I don't understand.") are correlated with students' proficiency at the 0.01 level. In contrast, Q43 ("I cooperate with classmates to improve my students.") and Q45 ("I try to understand the culture and background information of English-speaking countries.") are correlated at the .05 level. Social speaking strategies help those who are afraid of making mistakes feel safe, thus lower their anxiety and improve oral level. This research findings show that Social speaking strategies are conductive to oral proficiency, which promote communication. 
Table 4. Correlations among speaking strategies and English proficiency

\begin{tabular}{lll}
\hline Category & & Correlation Matrix \\
\hline Direct & Memory speaking strategies & .077 \\
Strategies & Cognitive speaking strategies & $.304^{* *}$ \\
& Compensation speaking strategies & $.291^{* *}$ \\
Indirect & Meta-cognitive speaking strategies & $.342^{* *}$ \\
Strategies & Affective speaking strategies & $.374^{* *}$ \\
& Social speaking strategies & $.560^{* *}$ \\
\hline
\end{tabular}

Note. **. Correlation is significant at the 0.01 level (2-tailed); *. Correlation is significant at the 0.05 level (2-tailed).

\section{Conclusions}

This study has demonstrated English speaking strategies used by Chinese High School Students of International Department, and the major findings are summarized as follows. Firstly, Chinese High School Students of International Department use speaking strategies at a medium level. Of the six broad categories, Memory speaking strategies are the most commonly used speaking learning strategies, followed by Compensation speaking strategies, Metacognitive speaking strategies, Cognitive speaking strategies, Affective speaking strategies and Social speaking strategies. Secondly, there are differences between higher achievers and lower achievers' use of speaking strategies. In general, higher achievers employ all the six broad categories more frequently than lower achievers and the differences in Cognitive speaking strategies, Metacognitive speaking strategies are significant $(\mathrm{p}=.000)$. Thirdly, Cognitive speaking strategies, Compensation speaking strategies, Metacognitive speaking strategies, Affective speaking strategies and Social speaking strategies are significantly correlated with students' English proficiency. In contrast, there is no significant correlation between Memory speaking strategies and the English proficiency of Chinese High School Students of International Department.

Good learning habits and active learning strategies are crucial in the process of language learning. In this way, some pedagogical implications can be inferred from this study. First and foremost, teachers should systematically introduce and reinforce speaking strategies training, which would be of great help to improve the oral English proficiency of Chinese High School Students of International Department. This aligns with Nakatani (2005) that participants in the strategy training group significantly outperformed the control group in their oral proficiency test scores. Specifically, different speaking strategies influence oral English proficiency negatively or positively. Thus, teachers should avoid negative speaking strategies and pay attention to the positive speaking strategies. For example, the correlation between Social speaking strategies and the oral English proficiency of Chinese High School Students of International Department is the highest among the six broad categories. Thus, more emphasis should be paid to students' acquisition of Social speaking strategies. Second, learners should pay attention to strategy use and develop a good habit of strategy use in oral English learning. In fact, "the effectiveness of all language learning strategies is determined by the learners' management of those strategies" (Wen \& Johnson, 1997, p. 39). Besides, the formation of effective English speaking strategies, which demands consistency and perseverance, may take a long time to realize.

\section{Acknowledgements}

This work was supported by Special project of Ideological and political work of Philosophy and Social Sciences Research in Jiangsu Universities (Grant No. 2021SJB1305), and Key Program of Teaching Reform in Yangzhou University (Grant No. YZUJX2017-10A).

\section{References}

Afflerbach, P., Pearson, P. D., \& Paris, S. G. (2008). Clarifying Differences Between Reading Skills and Reading Strategies. The Reading Teacher, 61(5), 364-373. https://doi.org/10.1598/RT.61.5.1

Arnold, J. (2000). Seeing through listening comprehension exam anxiety. Tesol Quarterly, 34(4), 777-786. https://doi.org/10.2307/3587791

Bai, R., Hu, G., \& Gu, P. Y. (2014). The Relationship Between Use of Writing Strategies and English Proficiency in Singapore Primary Schools. Asia-Pacific Education Researcher, 23(3), 355-365. https://doi.org/10.1007/s40299-013-0110-0

Barrot, J. (2016). ESL Learners' Use of Reading Strategies Across Different Text Types. Asia-Pacific Education Researcher, 25(5), 883-892. https://doi.org/10.1007/s40299-016-0313-2

Berne, J. E. (2004). Listening Comprehension Strategies: A Review of the Literature. Foreign Language Annals, 37(4), 521-531. https://doi.org/10.1111/j.1944-9720.2004.tb02419.x 
Canagarajah, A. S. (2011). Codemeshing in Academic Writing: Identifying Teachable Strategies of Translanguaging. The Modern Language Journal, 95(3), 401-417. https://doi.org/10.1111/j.1540-4781.2011.01207.x

Carson, J., \& Longhini, A. (2002). Focusing on Learning styles and Strategies: A Diary Study in an Immersion Setting. Language Learning, 2, 401-438. https://doi.org/10.1111/0023-8333.00188

Chamot, A. (1987). The learning strategies of ESL students. In A. Wenden \& J. Rubin (Eds.), Learner strategies in language learning (pp. 71-83). Englewood Cliffs, New Jersey: Prentice-Hall.

Chen, S.-Q. (1990). A study of communication strategies in interlanguage production by Chinese EFL learners. Language Learning, 40(2), 155-187. https://doi.org/10.1111/j.1467-1770.1990.tb01332.x

Chu, R. H. N. (2008). Shynesss and EFL learning in Taiwan: A study of shy and non-shy college students' use of strategies, foreign language anxiety, motivation, and willingness to communicate. Doctoral Thesis. University of Texas at Austin.

Ellis, R. (1994). The study of second language acquisition. Shanghai: Shanghai Foreign Language Education Press.

Huang, X. H. (1984). An investigation of learning strategies in oral communication that Chinese efl learners in china employ (p. 165). Chinese.

McDonough, S. H. (1995). Strategy and Skill in Learning a Foreign Language. London: Edward Arnold.

Nakatani, Y. (2005). The effects of awareness-raising training on oral communication strategy use. Modern Language Journal, 89, 76-91. https://doi.org/10.1111/j.0026-7902.2005.00266.x

O’Malley, J., \& Chamot, A. (1990). Learning strategies in second language acquisition. Cambridge: Cambridge University Press. https://doi.org/10.1017/CBO9781139524490

Oxford, R. (1989). Use of language learning strategies: A synthesis of studies with implications for strategy training. System, 17(2), 235-247. https://doi.org/10.1016/0346-251X(89)90036-5

Oxford, R. (1990). Language learning strategies: What every teacher should know. Rowley Mass: Newbury House.

Oxford, R., \& Crookall, D. (1989). Research on language learning strategies: Methods, findings, and instructional issues. Modern Language Journal, 73, 404-419. https://doi.org/10.1111/j.1540-4781.1989.tb05321.x

Rabab'ah, G. (2016). The Effect of Communication Strategy Training on the Development of EFL Learners' Strategic Competence and Oral Communicative Ability. Journal of Psycholinguistic Research, 45(3), 625-651. https://doi.org/10.1007/s10936-015-9365-3

Rubin, J. (1987). Learner strategies: Theoretical assumptions, research, history, and typology. In A. Wenden \& J. Rubin (Eds.), Learning strategies in language learning (pp. 14-25). Englewood Cliffs, NJ: Prentice Hall.

Shannon, S. V. (2008). Using metacognitive strategies and learning styles to create self-directed learners. Institute for Learning Styles Journal, 1, 14-31.

Shen, C. P. (2009). An empirical study of adult's oral English learning strategies in open education model. Journal of Xiamen Radio and TV University, 3, 9-13.

Tan, Y. H., \& Tan, S. C. (2010). A metacognitive approach to enhancing Chinese language speaking skills with audioblogs. Australasian Journal of Educational Technology, 26(7), 1075-1089. https://doi.org/10.14742/ajet.1035

Wen, Q., \& Johnson, R. K. (1997). L2 learner variables and English achievement: A study of tertiary-level English majors in China. Applied Linguistics, 18(1), 27-48. https://doi.org/10.1093/applin/18.1.27

Yunus, N. M., \& Singh, K. M. (2014). The use of indirect strategies in speaking: Scanning the MDAB students. Procedia-Social and Behavioral Sciences, 123, 204-214. https://doi.org/10.1016/j.sbspro.2014.01.1416

\section{Copyrights}

Copyright for this article is retained by the author, with first publication rights granted to the journal.

This is an open-access article distributed under the terms and conditions of the Creative Commons Attribution license (http://creativecommons.org/licenses/by/4.0/). 